\title{
The spectrum of biopsy-proven renal diseases in Korea
}

\author{
Beom Jin Lim ${ }^{(1 D}$ \\ Department of Pathology, Yonsei University College of Medicine, Seoul, Republic of Korea
}

Biopsy-proven kidney disease has been reported globally. Some of these data are based upon nationwide renal biopsy registries, while single-center-based data have also been provided from countries without registry cohorts. Because of the heterogeneity of study populations and numerous confounding components in retrospective studies, conclusions on the frequencies of renal diseases are not simple.

Definitions, diagnostic criteria, and terminologies in renal pathology have changed over the years. For instance, "mesangioproliferative glomerulonephritis (MsPGN)" is a descriptive term indicating increased number of mesangial cells but is not a disease entity. According to the underlying etiology, MsPGN could be further classified as immunoglobulin A (IgA) nephropathy, lupus nephritis, C3 glomerulopathy, and so on. Therefore, analyses using the term MsPGN in previous studies [1,2] cannot be directly compared to other reports using refined terminologies. Secondly, indications for performing renal biopsy in patients suspected of kidney disease are quite different among countries, institutions, and even clinicians. In each country, socioeconomic status and health policies may affect clinicians' decision making. Patient

Received January 30, 2020; Revised February 2, 2020;

Accepted February 3, 2020

Edited by Gheun-Ho Kim, Hanyang University, Seoul, Republic of Korea

Correspondence: Beom Jin Lim

Department of Pathology, Yonsei University College of Medicine, 50-1 Yonsei-ro, Seodaemun-gu, Seoul 03722, Republic of Korea. E-mail:bjlim@yuhs.ac

Copyright (C) 2020 by The Korean Society of Nephrology

(a) This is an open-access article distributed under the terms of the Creative Commons Attribution Non-Commercial License (http://creativecommons. org/licenses/by-nc-nd/4.0/), which permits unrestricted non-commercial use, distribution, and reproduction in any medium, provided the original work is properly cited. demographics, including age at biopsy, have tremendous impact on the frequencies of renal diseases. Therefore, readers should keep these things in mind when they compare the results of studies.

Table 1 summarizes the previous publications on frequencies of biopsy-proven renal diseases reported in China, Japan, and South Korea [1-9]. These data show major biopsy-proven glomerular diseases in East Asian countries. China has a huge population, and even a single-center study contains many biopsy cases. Japan and Korea have employed a regular mass screening of urine from primary school to high school since 1973 and 1998, respectively, for early detection of renal diseases [10]. This program might have affected the performance of renal biopsy.

In this issue of Kidney Research and Clinical Practice, Yim et al [9] report another study on the frequencies of renal diseases confirmed by renal biopsy in South Korea. This analysis was based on a retrospective review of 1,924 renal biopsy results from a single tertiary university hospital. After excluding pediatric cases (age $<15$ years) and kidney allograft biopsies, the most common primary glomerular disease was IgA nephropathy, and the most common secondary glomerulopathy was lupus nephritis. Minimal change disease was most frequently diagnosed in patients who were biopsied because of nephrotic syndrome.

Similar to other studies, this study has both weaknesses and strengths. Although the study comprised 13 years' experience at a single institution, the size of the study population was smaller than those of Chinese studies. Furthermore, the data and their interpretation were less refined than those of Japanese studies based upon the national renal biopsy registry. However, this study offers several interesting findings. IgA nephropathy was most prevalent in younger patients, whereas membranous ne- 
Table 1. Major biopsy-proven glomerular diseases in East Asian countries

\begin{tabular}{|c|c|c|c|c|c|c|c|c|c|c|}
\hline \multirow[b]{2}{*}{ Authors } & \multirow{2}{*}{$\begin{array}{l}\text { Publication } \\
\text { year }\end{array}$} & \multirow{2}{*}{ Country } & \multirow{2}{*}{$\begin{array}{l}\text { Renal } \\
\text { biopsy } \\
\text { registry }\end{array}$} & \multirow{2}{*}{$\begin{array}{l}\text { No. of } \\
\text { cases }\end{array}$} & \multicolumn{3}{|c|}{ Patients } & \multirow{2}{*}{$\begin{array}{l}\text { Most common } \\
\text { primary GN }\end{array}$} & \multirow{2}{*}{$\begin{array}{l}\text { Most common } \\
\text { secondary GN }\end{array}$} & \multirow{2}{*}{$\begin{array}{l}\text { Most common } \\
\text { cause of nephrotic } \\
\text { syndrome }\end{array}$} \\
\hline & & & & & Adults & Children & KT & & & \\
\hline Choi et al [3] & 2001 & Korea & No & 4,514 & 0 & 0 & 0 & $\begin{array}{l}\text { MCD (adults } \\
\text { and children) }\end{array}$ & $\begin{array}{l}\text { Lupus nephritis (adults) } \\
\text { HSPN (children) }\end{array}$ & $\begin{array}{l}\text { MCD (adults } \\
\text { and children) }\end{array}$ \\
\hline Chang et al [4] & 2009 & Korea & No & 1,818 & 0 & $x$ & $x$ & IgAN & Lupus nephritis & MCD \\
\hline Shin et al [1] & 2017 & Korea & No & 818 & 0 & $x$ & $x$ & MsPGN & Lupus nephritis & \\
\hline Zhang et al [5] & 2014 & China & No & 11,618 & 0 & 0 & $x$ & IgAN & Lupus nephritis & \\
\hline Zhou et al [2] & 2018 & China & No & 10,779 & 0 & $x$ & $x$ & IgAN & Lupus nephritis & \\
\hline Su et al [6] & 2019 & China & No & 2,725 & 0 & $x$ & $x$ & MN & HSPN & MN \\
\hline Sugiyama et al [7] & 2011 & Japan & Yes & 2,400 & 0 & 0 & 0 & IgAN & Diabetic nephropathy & \\
\hline Yokoyama et al [8] & 2012 & Japan & Yes & 2,802 & $\mathrm{O}$ (elderly) & $x$ & $x$ & MN & ANCA-related nephritis & MN \\
\hline Yim et al [9] & 2020 & Korea & No & 1,924 & 0 & $x$ & $x$ & IgAN & Lupus nephritis & MCD \\
\hline
\end{tabular}

ANCA, antineutrophil cytoplasmic antibody; GN, glomerulonephritis; HSPN; Henoch-Schönlein purpura nephritis; lgAN, immunoglobulin A nephropathy; KT, kidney transplantation; MCD, minimal change disease; MN, membranous nephropathy; MsPGN, mesangioproliferative glomerulonephritis.

phropathy was the dominant disease in elderly patients regardless of clinical presentation. The most frequently diagnosed glomerular disease in patients with hepatitis B or $\mathrm{C}$ seropositivity was IgA nephropathy rather than cryoglobulinemic glomerulonephritis.

Although these data cannot be assumed to be representative of the Korean population, the results are largely compatible with previous studies from Korean patients $[1,3,4]$. In the current study, thin basement membrane disease previously had an exceptionally high frequency but dramatically declined in recent years. As discussed in their interpretation, the indications for renal biopsy vary according to time period and institution. Over a certain period of time, renal biopsies might have been actively performed in young males who showed asymptomatic minor urinary abnormalities as qualification for military service. The fluctuating frequency of thin basement membrane disease and relatively younger age of this cohort could explain this unique finding.

Recent studies from China showed that membranous nephropathy is increasing $[6,11]$, and this result might be associated with air pollution by particulate matter 2.5 $\left(\mathrm{PM}_{2.5}\right)$ [12]. However, the current study [9] did not show any significant change in frequency of membranous nephropathy according to time course. Because the Korean study analyzed data until 2013 only, it is necessary to collect more recent cases and compare them with those of China.

As expected, a nationwide renal biopsy registry had many beneficial effects, including more reliable analyses of disease frequencies by coding the diagnoses in each institution and more reasonable clinicopathological correlations [13]. Future studies should be based on nationwide or multinational renal biopsy registries. An East Asian regional renal biopsy registry could be constructed by collaborative nephrologists in China, Japan, and Korea.

\section{Conflicts of interest}

The author has no conflicts of interest to declare.

\section{References}

[1] Shin HS, Cho DH, Kang SK, et al. Patterns of renal disease in South Korea: a 20-year review of a single-center renal biopsy database. Ren Fail 2017;39:540-546.

[2] Zhou Q, Yang X, Wang M, et al. Changes in the diagnosis of glomerular diseases in east China: a 15-year renal biopsy study. Ren Fail 2018;40:657-664.

[3] Choi IJ, Jeong HJ, Han DS, et al. An analysis of 4,514 cases of renal biopsy in Korea. Yonsei Med J2001;42:247-254.

[4] Chang JH, Kim DK, Kim HW, et al. Changing prevalence of glomerular diseases in Korean adults: a review of 20 years of experience. Nephrol Dial Transplant 2009;24:2406-2410.

[5] Zhang X, Liu S, Tang L, et al. Analysis of pathological data of renal biopsy at one single center in China from 1987 to 2012. Chin Med J (Engl) 2014;127:1715-1720.

[6] Su S, Yu J, Wang Y, Wang Y, Li J, Xu Z. Clinicopathologic correlations of renal biopsy findings from northeast China: a 
10-year retrospective study. Medicine (Baltimore) 2019;98: e15880.

[7] Sugiyama H, Yokoyama H, Sato H, et al. Japan Renal Biopsy Registry: the first nationwide, web-based, and prospective registry system of renal biopsies in Japan. Clin Exp Nephrol 2011;15:493-503.

[8] Yokoyama H, Sugiyama H, Sato H, et al. Renal disease in the elderly and the very elderly Japanese: analysis of the Japan Renal Biopsy Registry (J-RBR). Clin Exp Nephrol 2012; 16:903-920.

[9] Yim T, Kim SU, Park S, et al. Patterns in renal diseases diagnosed by kidney biopsy: a single-center experience. Kidney Res Clin Pract 2020;39:60-69.

[10] Ashida A, Shoji T, Honda S, et al. Benefits of incorporating urinary protein/creatinine ratio measurement in a school urine screening system: the experience of restructuring the school urinary screening system in Osaka Prefecture, Japan. Nephrology (Carlton) 2019;24:1142-1147.

[11] Chen L, Luodelete M, Dong C, et al. Pathological spectrum of glomerular disease in patients with renal insufficiency: a single-center study in Northeastern China. Ren Fail 2019; 41:473-480.

[12] Xu X, Wang G, Chen N, et al. Long-term exposure to air pollution and increased risk of membranous nephropathy in China. J Am Soc Nephrol 2016;27:3739-3746.

[13] Pesce F, Schena FP. Worldwide distribution of glomerular diseases: the role of renal biopsy registries. Nephrol Dial Transplant 2010;25:334-336. 